\title{
The Perception Of University Students On Intention To Use Malaysian Nasional Identity Card (My Kad) As A Multipurpose Card
}

\author{
Neeta Jayabalana, Charles Ramendran SPR, Vimala Kadiresan, Ramesh Kumar Moona Haji \\ Mohamed, Kogilavani Apadore, Thanaletchumi R.Letchumanan
}

\begin{abstract}
Majority of citizens still not aware of the functions of the identity card. Many Malaysian citizens reject to use this technology due to feel of discomfort and insecurity. Technology readiness index are one of the major factors that affect the intention to use identity card (IC) (My Kad). The key objective of our research is to identify the intention to use identity card as multiple user by University students. The respondents consist of 165 university students from the federal district of Kuala Lumpur. Data been collected using a set of questionnaires administered online using Google Forms software. The data was analysed by using SMART PLS- SEM 3.2.8. The results of the analysis show that students exhibit less attention to the use of MyKad as multi-purpose card technology. This is because MyKad is one of the personal identities and it is considered unsafe to use it as a multipurpose card. The implications of the study, drawbacks of the study as well as future research suggestions have been discussed in detailed
\end{abstract}

Index Terms: Optimism; Innovativeness; Discomfort; Insecurity; Intention to use; perceived ease of use.

\section{INTRODUCTION}

The Government of Malaysia has utilized smart cards as an identification purpose for Malaysian citizens and perpetual inhabitants matured twelve or a lot of since its official propelling on September 5, 2001. It consolidates one ATMEL 64K Electrically Erasable and Programmable Read Only Memory (EEPROM) microchip. It (chip) will contain little information including biometrics [1]. The Malaysian Government's Multipurpose Card or otherwise called MyKad is used like a multipurpose card which empowers its client to get to open and private administrations. It is viewed as one of the world's first smart identity card [2].

As indicated by the National Information Technology Council (NITC) (2009), one target of the MyKad is to give single protected ID stage to Government and private exchanges [3]. To date, MyKad venture has pulled in numerous private applications yet the take-up of open

Revised Manuscript Received on April 19, 2019.

Neeta Jayabalan, Faculty of Business, Accountancy and Management, SEGi University, Petaling Jaya, Selangor, Malaysia. Tunku Abdul Rahman, Kampar, Perak, Malaysia

Vimala Kadiresan, Faculty of Business Studies, Help University, Kuala Lumpur, Selangor, Malaysia

Ramesh Kumar Moona Haji Mohamed, Faculty of Business and Finance, University Tunku Abdul Rahman, Kampar, Perak, Malaysia

Kogilavani Apadore, Faculty of Business and Finance, University Tunku Abdul Rahman, Kampar, Perak, Malaysia

Thanaletchumi R.Letchumanan, Faculty of Business and Finance, University Tunku Abdul Rahman, Kampar, Perak, Malaysia
Charles Ramendran SPR, Faculty of Business and Finance, University

applications has been negligible. The board likewise announced that generally Nine hundred million RM has been put resources into MyKad venture, in addition to Six hundred million RM for the buy of twenty-two million smart cards [4]. To guarantee that MyKad application accomplishes its maximum capacity, different offices, for example, Malaysian Administrative Modernisation and Management Planning Unit (MAMPU), National Registration Department (JPN), NITC and Pos Malaysia Berhad are needed to collaborate. In the wake of spending such a sum on building up the venture, the utilization of MyKad is not restricted to ID reason just, however, it is additionally creating to perform distinctive access to Government organizations [5].

Malaysian population roughly reached 32 million but only about 16.2 million who are actively used smart card of Touch ' $\mathrm{n}$ Go, and more than eight million people are actively using the card which around RM5 million in daily transaction [6]. Touch ' $n$ Go company vision is in the electronic payment system for micro payment towards cashless society to become No.1. People still not aware of new technology, which makes life more convenience by; choose smart way to make payment. This situation indirectly told us that Malaysian still late in adopting new technology compare to developed countries, which already more advance in created cashless society [7].

Additionally, there also founded majority of citizens still did not aware of the functions of the identity card. Many Malaysian citizens reject to use this technology due to feel of discomfort and insecurity. Technology readiness index are one of the major factors that affect the intention to use identity card (IC) as Touch 'n Go among Malaysian citizens, which was developed by Parasuraman [8]. Malaysian had little understanding of benefits using identity card and the efforts needed to use it. In order to have a good understanding based on consumer intention on usage of identity card, we have chosen plaza toll in Malaysia to focus more on consumer use of identity card as Touch ' $n$ Go. The independent variable that we have to selected are Technology Readiness Index and one depending variable is intention to utilize The Technology Readiness is including of innovativeness, optimism, discomfort and insecurity. Do University students consider that Mykad as multiple user is 
easier than using multiple cards? The primary objective of our research is to identify intention to utilize identity card as multiple user by University students

\section{LITERATURE REVIEW AND THE UNDERLYING THEORY}

Technology Readiness (TR) and Technology Acceptance Model (TAM) are united to form TRAM model. TRAM model merges the Technology Readiness Index's ordinary individuality dimensions with TAM's system specific dimension that produce a more specific model [9]. Therefore, it can be used to explain how the personalities can affect the way of individual interact and use the technologies. Although the measurement of ease of use and usefulness in Technology Readiness (TR) is for common technology opinion such as individual specific whereas the Technology Acceptance Model (TAM) is for a designated system such as system-specific, they are considered as interrelated.

Technology Acceptance Model believes people intend to use the new technologies are affected by their intentions regarding the technology's usefulness and ease of use. There are total 3 variables in TAM which are intention to use, perceived usefulness as well as ease of use [10]. Perceived ease of use is people believe that free of effort is needed to exploit the new systems whereas perceived usefulness is known as people believe their performance can be improved by using the particular system. Intention to use means the effort and request of an individual to execute a behaviour [10]. The perceived features are assumed to affect the intention to adopt a new technologies and system and then influence the usage of actual system [9].

As these two models are interdependent, Technology Readiness is known as the general opinion of individual about the technology which is the vital variables involves in the Technology Acceptance Model. Therefore, past studies showed that general opinions of the individual effect on their intention on ease of use and usefulness [11]. Optimism has a negative relationship with perceive risks since they are positive thinking and willing to accept the technology with an open-minded and positive view. The innovative people have fewer complex views about the new technologies [12]. Insecurity people reject to use the technology due to their innate fear. Insecurity people concern in the technologies' reliability and confidentially of the data shared [12]. Discomfort dimension showed that people perceived command of technology is insufficient, believe the new product is not design for them and cause the feeling of depressed [12].

\section{RESEARCH FRAMEWORK}

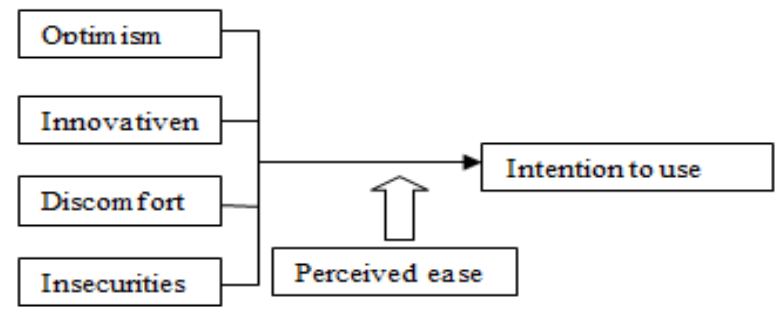

Figure 1
Base on discussion below are the hypothesis that have been developed: -

1. H1Discomfort shows negative relationship on intention to utilize Mykad

2. H2Innovativeness shows positive relationship on intention to utilize Mykad

3. H3Insecurity shows negative relationship on intention to utilize Mykad

4. H4Optimism shows positive relation on intention to utilize Mykad

5. H5Perceived ease of use have positive relation on intention to utilize Mykad

6. H6Perceived ease of use moderate the relation between Discomforts and intention to utilize Mykad

7. H7Perceived ease of use moderate the relation between Innovativeness as well as intention to utilize Mykad

8. H8Perceived ease of use moderate the relation between Insecurity and intention to utilize Mykad

9. H9Perceived ease of use moderate the relation between Optimism and intention to utilize Mykad

\section{METHODOLOGY}

Research methodology is vital for the improvement of studies. Quantitative a distinct research was utilized to gather numerical and quantifiable information. Consequently, primary and secondary information was gathered through survey to depict the hypothesis further. Sampling design was utilized to decide target population of respondents and population elements. Data processing portrayed the method for getting ready information and factual strategies for information investigation. Besides, we have directed pilot consider before appropriating the last questionnaire to respondents. Each progression was an urgent advance to guarantee the achievement and dependable result in this examination. Proceed with this examination with section 4 , as research result. There were different investigations which incorporate descriptive analysis, reliability, analysis and inferential analysis as plainly and connected to our exploration subject with the outcomes.

\section{RESULTS ANALYSIS}

First, measurement models of every construct have been examined for the dependability, validity of convergence and discrimination validity, before testing hypothetical models. Table 3 demonstrates the score found from measurement model. From Table 3, it is seen that all the loads are greater than 0.70 which is threshold proposed by Hair, Ringle and Sarstedt [13]. The average variance extracted (AVE) of every contract exceeds 0.5 value (Bagozzi and Yi, 1988) whereas composite reliability score $(\mathrm{CR})$ is greater than 0.7 value [13]. Thus, it can be concluded that Convergent conclusions are attained. 
The VIF also has been studied to test the possible multicollinearity issues (presented in Table 3). A value ranged below 5 of VIF values for every construct confirms satisfactory construct validity through multicollinearity lacking. It is also because the value falls significantly lower than 9 (minimum threshold) [14].

Table 4 shows that data for validity test of discrimination. As proposed by [15] and [16], AVE for every development must be greater correlation amongst them and anything else construction model. As presented in the Table 5, every construction meets this criteria suggesting construction has the validity of discrimination. Reference [13] shows that all measured variable item loads must be higher than cross-load by all by 0.1 (at least) to show the legality of discrimination enough. As shown in Table 5 contains all constructions meeting this criterion. Therefore, we can infer that the validity of discrimination is obtained.

Reference [17] also demonstrated the superior performances of this technique by Monte Carlo simulation study. Similarly, we also have tested discriminant validity utilizing this novel recommended method and all results presented in Table 6. There are two paths of utilizing HTMT to evaluate the discriminant validity: (1) as statistical test or
(2) as a criterion. For the second one (as criterion), if HTMT value is higher than HTMT.85 value of 0.85 [18], or HTMT.90 value of 0.90 [19] then there will be discriminant validity problem.

To evaluate for fitness of measurement model, this research shows similarity with the guide of [20] which highlights the fitness of measurement models. The authors suggest that researchers must study the saturated model and also Standardized Root Mean Square Residual (SRMR) at 95\% bootstrap quantile. The authors further suggest that SRMR is the only approximate model fit criterion used for PLS path modelling purpose. In addition, the dG and dULS [21] which are distance measures that combine more than single way to calculate the discrepancy between matrices have been also accentuated to contribute in model fitness index at PLS [20]. Table 6 presents that the $\mathrm{dG}$ and the dULS are 0.523 and 0.479 . It reflects a signal to well-fitted measurement model [21]. Moreover, SRMR is 0.048. This is lower than the cut-off of 0.08 [22] suggesting that this measurement model fits our study.

Table 1 Convergent validity

\begin{tabular}{|c|c|c|c|c|}
\hline Items & Loadings & CR & AVE & VIF \\
\hline D1 & 0.861 & 0.843 & 0.729 & 1.265 \\
\hline D4 & 0.846 & & & 1.265 \\
\hline IN1 & 0.81 & 0.909 & 0.668 & 3.107 \\
\hline IN2 & 0.734 & & & 2.607 \\
\hline IN3 & 0.85 & & & 2.806 \\
\hline IN4 & 0.858 & & & 2.898 \\
\hline IN5 & 0.827 & & & 2.101 \\
\hline INS3 & 0.96 & 0.952 & 0.909 & 3.034 \\
\hline INS4 & 0.947 & & & 3.034 \\
\hline INT1 & 0.911 & 0.946 & 0.853 & 2.714 \\
\hline INT2 & 0.926 & & & 3.397 \\
\hline INT3 & 0.934 & & & 3.855 \\
\hline OP1 & 0.901 & 0.951 & 0.796 & 4.014 \\
\hline OP2 & 0.861 & & & 2.983 \\
\hline OP3 & 0.924 & & & 4.664 \\
\hline OP4 & 0.912 & & & 4.422 \\
\hline OP5 & 0.861 & & & 2.592 \\
\hline PEU1 & 0.917 & 0.973 & 0.822 & 4.488 \\
\hline PEU2 & 0.896 & & & 4.144 \\
\hline PEU3 & 0.956 & & & 4.771 \\
\hline PEU4 & 0.976 & & & 4.692 \\
\hline PEU5 & 0.976 & & & 4.234 \\
\hline PEU6 & 0.948 & & & 4.488 \\
\hline PEU7 & 0.892 & & & 4.327 \\
\hline
\end{tabular}

Table 2 Fornell \& Lackers

\begin{tabular}{|c|c|c|c|c|c|c|}
\hline & Discomfort & Innovativeness & Insecurity & Intention to use & Optimism & PEU \\
\hline Discomfort & 0.854 & & & & & \\
\hline Innovativeness & 0.659 & 0.833 & & & & \\
\hline Insecurity & 0.508 & 0.339 & 0.953 & & & \\
\hline Intention to use & 0.626 & 0.616 & 0.602 & 0.924 & & \\
\hline Optimism & 0.636 & 0.694 & 0.494 & 0.689 & 0.892 & \\
\hline PEU & 0.765 & 0.664 & 0.508 & 0.815 & 0.657 & 0.94 \\
\hline
\end{tabular}


International Conference on Recents Advancements in Engineering and Technology (ICRAET-18) |15th and 16th March 2019|Siddhartha Institute of Technology \& Sciences, Telangana, India.

Table 3 Cross Loadings

\begin{tabular}{|c|c|c|c|c|c|c|}
\hline & Discomfort & Innovativeness & Insecurity & Intention to use & Optimism & PEU \\
\hline D1 & 0.861 & 0.713 & 0.356 & 0.546 & 0.669 & 0.696 \\
\hline D4 & 0.846 & 0.405 & 0.515 & 0.521 & 0.411 & 0.623 \\
\hline IN1 & 0.568 & 0.847 & 0.349 & 0.449 & 0.586 & 0.537 \\
\hline IN2 & 0.397 & 0.784 & 0.274 & 0.483 & 0.462 & 0.464 \\
\hline IN3 & 0.648 & 0.849 & 0.278 & 0.57 & 0.684 & 0.647 \\
\hline IN4 & 0.566 & 0.851 & 0.24 & 0.535 & 0.565 & 0.577 \\
\hline INS3 & 0.483 & 0.337 & 0.96 & 0.609 & 0.475 & 0.513 \\
\hline INS4 & 0.486 & 0.308 & 0.947 & 0.535 & 0.466 & 0.477 \\
\hline INT1 & 0.64 & 0.626 & 0.531 & 0.911 & 0.631 & 0.824 \\
\hline INT2 & 0.563 & 0.575 & 0.558 & 0.926 & 0.638 & 0.78 \\
\hline INT3 & 0.523 & 0.499 & 0.582 & 0.934 & 0.641 & 0.683 \\
\hline OP1 & 0.524 & 0.663 & 0.415 & 0.577 & 0.901 & 0.608 \\
\hline OP2 & 0.559 & 0.491 & 0.378 & 0.558 & 0.861 & 0.564 \\
\hline OP3 & 0.627 & 0.689 & 0.398 & 0.642 & 0.924 & 0.658 \\
\hline OP4 & 0.503 & 0.626 & 0.44 & 0.637 & 0.912 & 0.577 \\
\hline OP5 & 0.618 & 0.614 & 0.56 & 0.65 & 0.861 & 0.592 \\
\hline PEU1 & 0.739 & 0.653 & 0.535 & 0.822 & 0.695 & 0.917 \\
\hline PEU2 & 0.73 & 0.569 & 0.556 & 0.786 & 0.655 & 0.896 \\
\hline PEU3 & 0.741 & 0.609 & 0.495 & 0.782 & 0.555 & 0.956 \\
\hline PEU4 & 0.711 & 0.633 & 0.465 & 0.777 & 0.628 & 0.976 \\
\hline PEU5 & 0.732 & 0.644 & 0.451 & 0.771 & 0.618 & 0.976 \\
\hline PEU6 & 0.749 & 0.697 & 0.498 & 0.768 & 0.642 & 0.948 \\
\hline PEU7 & 0.666 & 0.609 & 0.405 & 0.724 & 0.62 & 0.892 \\
\hline
\end{tabular}

Table 4 HTMT

\begin{tabular}{|c|c|c|c|c|c|c|}
\hline & Discomfort & Innovativeness & Insecurity & Intention to use Optimism & PEU & Saturated Model \\
\hline Discomfort & & & & & SRMR & 0.072 \\
\hline Innovativeness & 0.887 & & & & d_ULS & 1.537 \\
\hline Insecurity & 0.678 & 0.39 & & & d_G & 1.83 \\
\hline Intention to use & 0.822 & 0.689 & 0.662 & & & \\
\hline Optimism & 0.824 & 0.768 & 0.535 & 0.743 & & \\
\hline PEU & 0.896 & 0.68 & 0.489 & 0.809 & & \\
\hline
\end{tabular}

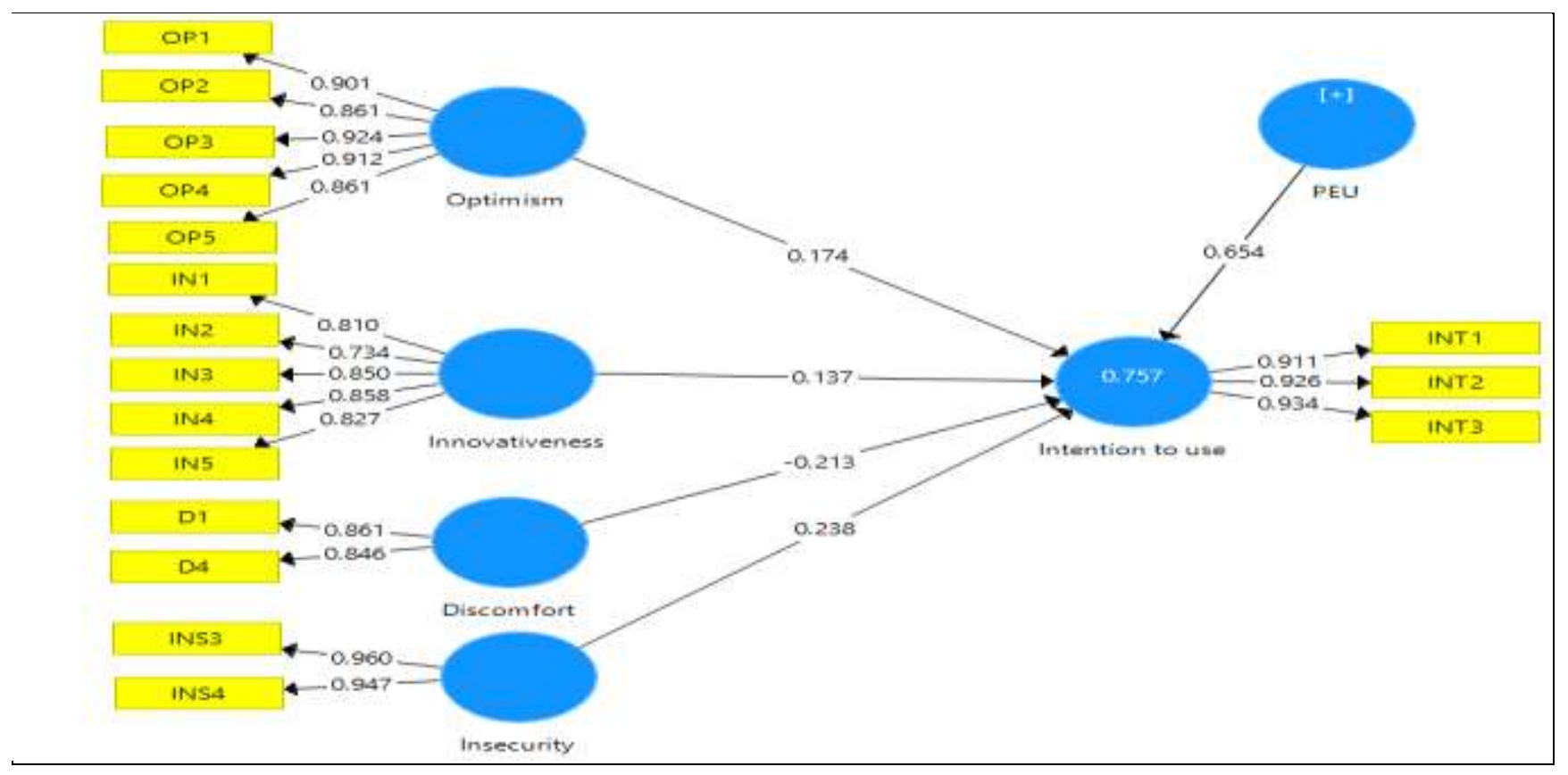

Figure 2 Measurement Model 


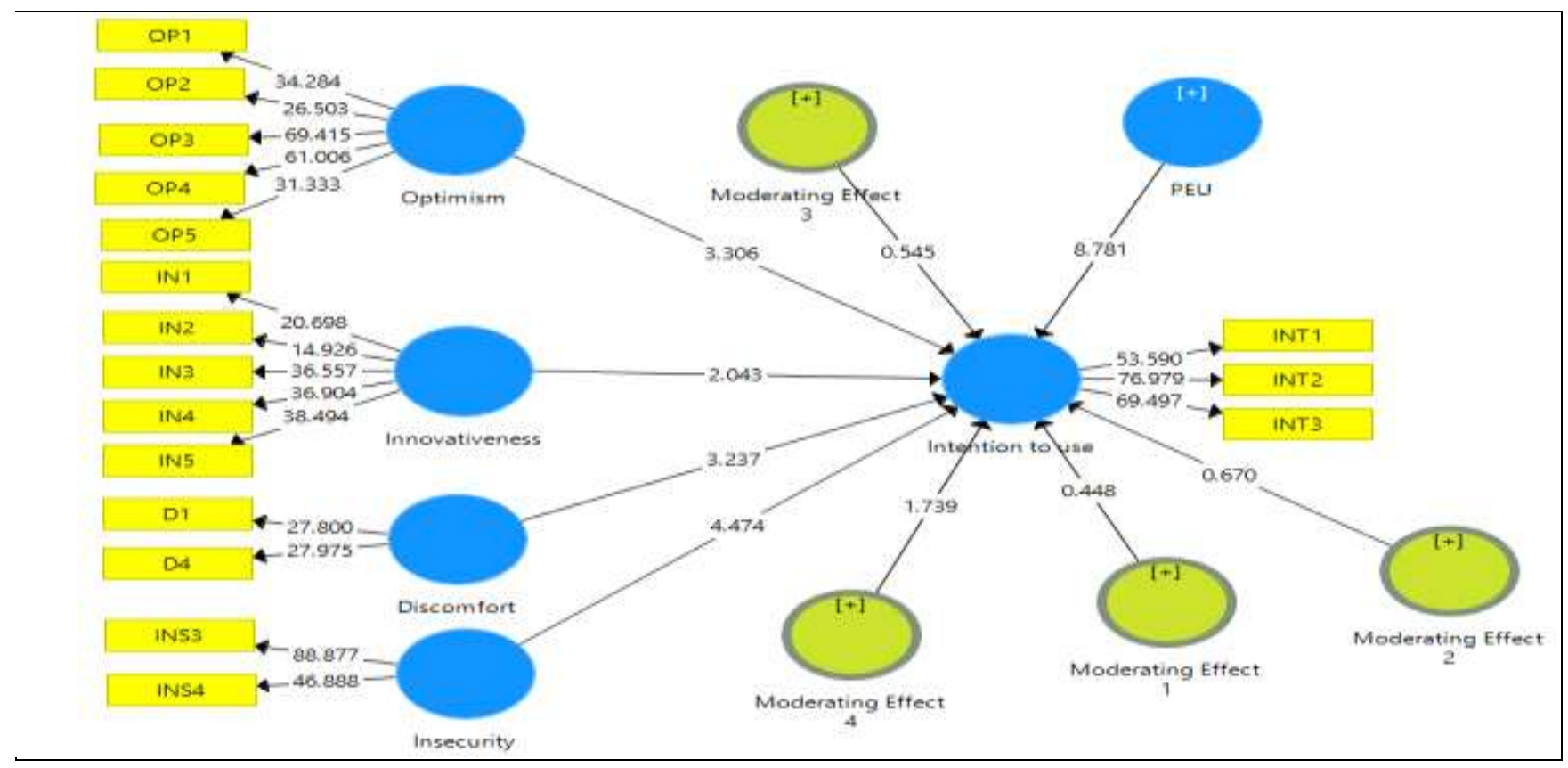

Figure 3 Structural Model

Table 5 Hypothesis results

\begin{tabular}{|c|c|c|c|c|c|c|c|c|c|}
\hline Hypothesis & $\begin{array}{c}\text { Beta } \\
\text { Value }\end{array}$ & $\begin{array}{c}\text { Std } \\
\text { error }\end{array}$ & $\begin{array}{c}\text { T } \\
\text { Value }\end{array}$ & $\begin{array}{c}\mathbf{P} \\
\text { Values }\end{array}$ & $\mathbf{L L}$ & $\mathbf{U L}$ & $\mathbf{R 2}$ & Q2 & Decision \\
\hline Discomfort $->$ Intention to use & -0.228 & 0.071 & 3.237 & 0.001 & -0.354 & -0.123 & 0.751 & 0.0640 .601 & Supported \\
\hline Innovativeness -> Intention to use & 0.145 & 0.071 & 2.043 & 0.021 & 0.019 & 0.252 & & 0.03 & Supported \\
\hline Insecurity $->$ Intention to use & 0.2 & 0.045 & 4.474 & 0 & 0.125 & 0.271 & & 0.109 & Supported \\
\hline Optimism -> Intention to use & 0.264 & 0.08 & 3.306 & 0 & 0.136 & 0.399 & & 0.095 & Supported \\
\hline PEU -> Intention to use & 0.666 & 0.076 & 8.781 & 0 & 0.548 & 0.792 & & 0.629 & Supported \\
\hline $\begin{array}{l}\text { Moderating Effect Dis -> Intention to } \\
\text { use }\end{array}$ & -0.048 & 0.072 & 0.67 & 0.251 & -0.186 & 0.052 & & 0.005 & $\begin{array}{c}\text { Not } \\
\text { Supported }\end{array}$ \\
\hline $\begin{array}{l}\text { Moderating Effect Inn -> Intention to } \\
\text { use }\end{array}$ & 0.036 & 0.081 & 0.448 & 0.327 & -0.09 & 0.17 & & 0.001 & $\begin{array}{l}\text { Not } \\
\text { Supported }\end{array}$ \\
\hline $\begin{array}{l}\text { Moderating Effect Ins -> Intention to } \\
\text { use }\end{array}$ & -0.041 & 0.075 & 0.545 & 0.293 & -0.168 & 0.077 & & 0.003 & $\begin{array}{c}\text { Not } \\
\text { Supported }\end{array}$ \\
\hline $\begin{array}{l}\text { Moderating Effect OPT -> Intention to } \\
\text { use }\end{array}$ & 0.122 & 0.07 & 1.739 & 0.041 & 0.009 & 0.231 & & 0.028 & Supported \\
\hline
\end{tabular}

\section{DISCUSSION OF FINDINGS}

In this study, there found 165 respondents who have filled the questionnaire. Majority of the respondents belongs to the age ranged from 21 to 25 years, Nationality Status is Malaysian, majority Race were mislaying and Chinese follow by Indian. While education level of respondents is mostly undergraduate. In the pilot study, the reliability test value came as 0.856 , which means the questionnaire is ideal and reliable.

A. Result of the Smart PLS 3.2.7 Bootstrapping Results

These results are collected from 165 respondents and evaluated by Smart PLS 3.2.8. to assess the statistical importance of path coefficient, Reference [23] recommended a least threshold of $1.65 \mathrm{t}$-statistics value at $\mathrm{p}$ less than or equal to 0.1 confidence interval. Likewise, Lowry and Gaskin [24] espouse that effect size of 0.02, 0.15 and 0.35 indicate a small, medium and large effect, respectively. Reference [25] pointed that $\mathrm{R} 2$ values of 0.25 , 0.50 and 0.75 reflect weak, moderate and substantial values.

$\mathrm{R}$ Square implied to detect the coefficient for determination in dependent construct. Reference [26] states that for a strong, moderate and weak R2 need 0.67, 0.33 and 0.19. Besides, according to Reference [27], the R2 value equal to 0.75 means strong, 0.5 means moderate, and 0.25 means weak. On the other hand, Falk and Miller [28] suggested that $\mathrm{R}$ square must be bigger or equal to 0.10 , for the variance described of a certain endogenous construct to be considered adequate. To obtain the significance level, the PLS bootstrapping options were initiated utilizing $5000 \mathrm{sub}$ samples [27]. Hence, based on the studies, the R2 value for researcher's study is found Large $(0.751)$, presented in Table 7.

Published By:

Blue Eyes Intelligence Engineering

\& Sciences Publication 
Next, researchers have to know on the F Square to know the power of this model. The purpose to have the Effective Size (f square) was to help researchers to determine the best model. By referring to the table 7 , it has a nearly large effect size, In conclusion, researchers had known that researchers' model had meet the requirement of the Inner Inner Model.

Table 7 shows the entire hypothesis stated down from $\mathrm{H} 1$ to H4. It contains a T-statistics value for every hypothesis. When the hypothesis become significant, the value of $t$ is greater than $1.645(\mathrm{p}<0.05), \mathrm{t}$-value greater than $2: 33$ (p $<0.01)$ for 1 -tail test, $\mathrm{t}$-value greater than $1.96(\mathrm{p}<0.05)$ or $\mathrm{t}$ value greater than $2: 58$ ( $\mathrm{p}<0.01)$. Table 7 indicates that there are three hypotheses, which are H1, H2, H3, H4 H5 and $\mathrm{H} 9$ are significant because the lower limit the upper limit for the hypothesis is in a positive value, so the the remaining $\mathrm{H} 6, \mathrm{H} 7$ and $\mathrm{H} 8$ are not supported.

\section{IMPLICATION OF THE STUDY}

\section{A. Theoretical Contribution}

This research assesses the well-known model in literature, Technology Readiness and Technology Acceptance Model (TRAM). This research reveals that all 4 kinds of technology readiness (like optimism, discomfort, insecurity and innovativeness have effects on the intention to use the technology. The framework establishes based on models and journals of past research paper.

According to the past research did by [29], they mentioned that there found a positive relation between the optimism and intention to utilize a technology. The result in this study is same as past studies where optimism has the significant positive relation with the aim to utilize the identity card as multipurpose card. Past studies prove that optimism act as contributors that can advance the level of technology readiness and driver of the intention to utilize technology. This study agrees with the statement that the more optimistic an individual, the higher the intention to use the technology. An optimist may have fearlessness on the new technology and highly accept the new idea, so they are willing to use MyKad as Multipurpose card.

The theory of TRAM Model suggested that innovativeness has the positive effect on behavioral intention to use the technologies. Past studied reported that innovative people seek for self-fulfillment when using the advanced technology. They only take the risk to try the products at the forefront when there is the latest technology. The innovativeness dimension is also the driver of the intention to utilize the technology based on TRAM model. In our study, they might be perceived that using the identity card (IC) as multipurpose card is an innovative way. KL people have high excitement and self- fulfillment to use the identity card as multipurpose card because they might perceive that the features and the new way of using identity card are attractive and innovative. Thus, high innovative people will increase their intention to use the identity card (IC) as multipurpose card.

For the discomfort dimension, this study agrees with the statement that there found a significant negative relation Model by referred to the measurement requirement for the hypothesis had become significant which is zero. Similarly,

between discomfort and intention to utilize identity card as multipurpose card in Malaysia. Based on the TRAM, discomfort is inhibitors and negative beliefs towards technology. The results are consistent with past researches where the higher the discomfort, the lower the intention to use the particular technology.

Insecurity dimension is also known as inhibitors and negative belief towards the acceptance of new technology in this research. The outcomes are matched with the explanation of the theory from past study. The result shows that the greater the insecurity feeling, the smaller the intention to use the IC as Multipurpose card. Past studied mentioned that insecurity feeling refers to the absence of trust in technologies and worries about its potential danger. When we applied the theory in this study, it reflects insecurity people worried about the danger of using IC as Multipurpose card, resulting in low intention to use the technology.

\section{B. Managerial Implications}

This part elaborates the relation between independent variables (optimism, innovativeness, discomfort, and insecurity) and the dependent variables (intention to use).

Optimism is positively correlated with intention to use identity card (IC) as multipurpose card so the government should concern about it. Citizens who are optimism will tend to increase the intention to use identity card as multipurpose card. High optimism is resulting from the customer who has a positive feeling and view about the new invention. In contrast, citizens with low optimism will reduce the intention to use the identity card as multipurpose card. Therefore, the government should eliminate the negative view and emotion when the consumer experiences unexpected issues with the new technologies. The government should take direct responsibility for solving; handling the optimism issues and develop optimistic strategy to increase the intention to utilize the identity card as multipurpose card.

Besides, innovativeness should be focused because it is also positively correlated with the intention to use the identity card (IC) as multipurpose card. High innovative people will have more faith in new technology, highly accept and try the new technologies. Increase the innovativeness of product is important to increase the intention to utilize the product. People intention to utilize the product is lower if the product is not innovativeness. Government is suggested to increase the innovativeness by adding some features into identity card to attract the customer to use it as multipurpose card. The features must be innovative and gain competitive advantages to increase the customer' intention to use it. The new features can create product differentiation and should be able to bring more benefits to the customer.

Discomfort variable is the highest positively correlated to intention to use identity card as multipurpose card. High discomfort will result in citizens have lesser intention to use identity card as Multipurpose card while low discomfort 
results in high intention to use it. People with low technological knowledge cannot control over technologybased products and services tend to have more discomfort feeling. Therefore, the guideline is necessary to help them to better understand the functions and way to use identity card as multipurpose card. An advertisement is a channel that used to explain the benefits of using it and minimize the feeling of discomfort. Malaysia citizens needs to be convinced of the values and benefits of having the identity card as multipurpose card by the various way such as mass media promotions and school program to raise the social influences of identity card usage.

High insecurity feeling leads to lower intention to use identity card as multipurpose card. Insecurity, where the result indicated the lowest, involves people may worry about the danger and criticize the ability of its function. People are prepared to take the risk of utilizing the technology only when they believe they will receive a large benefit over using the new technology. So, the security of the identity card should be improved to the higher level in order to raise the confidence to use identity card as multipurpose card. Technology experts are hired to develop and enhance security level, solve any security issues and ensure the identity card can function and work as multipurpose card properly. Malaysians should be noticed about the security characteristics of the identity card such as read-protected characteristics of the card, and encryption technology. The government should mention that the Mykad has the same security level as credit cards and ATM cards. This may minimize their fear and understand the security features.

The innovativeness, optimism, insecurity and discomfort variables can affect the intention to utilize the identity card (IC) as multipurpose card. Researchers suggest that people requirements and needs must fully understand so that the identity card (IC) can be widely accepted and use as the Multipurpose card.

\section{Limitation of the Study}

Throughout this study, we encountered some drawbacks. The first limitation is the content of the questionnaire. Sometimes respondents might difficult to answering the questions because some of the sentences and word in the questions may be difficult to understand. Therefore, this situation will reduce the effectiveness of our result. Thus, in order to reduce the respondents randomly to answering the questionnaire, we are willing to explain to them the questions for those who have difficulty to answering the questionnaires and patiently waiting them to answer the questionnaire.

In addition, the second limitation of this study is scope of coverage. As our study is based on university students only, therefore it cannot represent to the entire Malaysia, which will lead to limited views of the respondents. Therefore, we try to expand more time on there to finding more respondents.

Third, participation of respondents may be difficult for every respondent to participate in the questionnaire because some respondents are not free to answer the questionnaire. Moreover, sometimes the questions are quite sensitive might also let the respondent bias in answering the questionnaires. At the same time, some of them will give excuses they are not free or busy because they are unwilling to answer the survey. This situation can lead the sample size become smaller if the numbers of respondents are less. In order to reduce the situation of rejection, we will persuade and explain the main reasons for the investigation so that they believe and willing to cooperate with us.

Furthermore, number of coverages also is a limitation of this study. Since our study is only based on university students, therefore it cannot represent to entire Malaysia, which will lead to limited respondents. Thus, in this study we just received 165 respondents, so we try to expand more time to finding more respondents to increase the number of respondents and also make our study more convincing.

Lastly, lack of information also limited to this research. In this research, the data we can find mainly comes from internet source which are journal and also the article. Some of the data was locked and we need to buy the copyright. Besides that, some of the data that we find is too old and can't help in our research. In order to complete the study, we just only managed to obtain complete data for all independent and dependent variables from year 2010 until year 2018. A limited time frame may have an impact on the results because longer time periods may provide different results.

\section{Recommendations for Future Research}

In the future research, we recommend that given the sufficient time to researcher to research the study such as more than half year, this can lead the researcher have enough time to find out more of the relevant and useful data. Researcher also can find out other independent variable that will influence people's intention to use. Besides that, if have enough time researcher also can distribute the questionnaire in other place not just among university students

Second recommendation is researcher can consider extending the study coverage to whole Malaysia and not just among university students. Expand research may make the study more reasonable because different locations have different opinions with different respondents. Moreover, researcher also may receive large amount of the sample size when the respondents is increase. Along with the number of respondents increases, the data we collect will also increase, which will make our data analysis results more convincing.

In addition, future researchers may consider simplifying the questionnaire and making it easier for respondents to understand it. It will allow respondents to easily understand the questions without feeling confused when answering the questionnaire. When questions are easy to understand, respondents know the true meaning behind the question in order to more accurately express themselves, which allows researchers to obtain more accurate results.

Lastly, future researcher can add on more independent variable other that the four independent variable that include in this research to explore the citizen's intentions to utilize identity card as multipurpose card. With more independent variables, researchers will have a clearer understanding and opinion of the scope of learning. 


\section{CONCLUSION}

This study was carried out to enhance the understanding on intention to use identity card (IC) as multipurpose card in Malaysia. The 4 factors consist of optimism, discomfort, innovativeness and insecurity can affect the intention to utilize the identity card (IC) as Multipurpose card. Some limitations and recommendation also provided by the researchers. In short, this research is useful to increase the intention to use the identity card as multipurpose card in Malaysia.

\section{REFERENCES}

1. Loo WH, Yeow PH, Chong SC. User acceptance of Malaysian government multipurpose smartcard applications. Government Information Quarterly. 2009 Apr 1;26(2):358-67.

2. National Registration Department of Malaysia, (2016). Retrieved

from https://www.jpn.gov.my/en/informasimykad/introduction -to-mykad/\#1458809227971-eff21ffd-46e7

3. Sin Tan K, Choy Chong S, Lin B, Cyril Eze U. Internetbased ICT adoption among SMEs: Demographic versus benefits, barriers, and adoption intention. Journal of enterprise information management. 2010 Jan 5;23(1):27-55.

4. Bertozzi F, Ali CM, Gul FA. Information System Development and Management; Hands on Practice. International Journal For Research In Business, Management And Accounting (ISSN: 2455-6114). 2017 Feb 28;3(2):51-64.

5. Venkatesh V, Morris MG, Davis GB, Davis FD. User acceptance of information technology: Toward a unified view. MIS quarterly. 2003 Sep 1:425-78.

6. The Star (2016), Touch 'n Go to launch two financial technology products, Retrieved from https://www.thestar.com.my/business/businessnews/2016/09/02/touch-n-go-to-launch-two-financialtechnology-products/\#5YCEpcS7bJmlvLku.99

7. The Star (2019), Paving the way forward, Retrieved from

https://www.thestar.com.my/news/nation/2019/02/03/pav ing-the-way-forward-one-of-the-biggest-players-in-theewallet-industry-tng-digital-strives-to-cha/

8. Parasuraman A, Colby CL. An updated and streamlined technology readiness index: TRI 2.0. Journal of service research. 2015 Feb;18(1):59-74.

9. Godoe P, Johansen T. Understanding adoption of new technologies: Technology readiness and technology acceptance as an integrated concept. Journal of European Psychology Students. 2012 May 6;3(1).

10. Esen M, Erdogmus N. Effects of technology readiness on technology acceptance in e-HRM: Mediating role of perceived usefulness. The Journal of Knowledge Economy \& Knowledge Management. 2014; 9:7-21.

11. Ali B, Nawanira G, Nasidib Y, Bamgbadec JA. Examining technology readiness constructs: a validation study. Journal of Advanced Research in Business and Management Studies. 2016;3(1):71-84.

12. BA?GÖZE P. Integration of Technology Readiness (TR) into the Technology Acceptance Model (TAM) for mshopping. International Journal of Scientific Research and Innovative Technology. 2015;2(3):26-35.

13. Hair JF, Ringle CM, Sarstedt M. Partial least squares structural equation modeling: Rigorous applications, better results and higher acceptance. Long range planning. 2013 Mar 14;46(1-2):1-2.

14. Yong AG, Pearce S. A beginner's guide to factor analysis: Focusing on exploratory factor analysis.
Tutorials in quantitative methods for psychology. 2013 Oct;9(2):79-94.

15. Fornell C, Larcker DF. Evaluating structural equation models with unobservable variables and measurement error. Journal of marketing research. 1981 Feb;18(1):3950.

16. Fornell C, Johnson MD, Anderson EW, Cha J, Bryant BE. The American customer satisfaction index: nature, purpose, and findings. Journal of marketing. 1996 Oct;60(4):7-18.

17. Henseler J, Ringle CM, Sarstedt M. A new criterion for assessing discriminant validity in variance-based structural equation modeling. Journal of the academy of marketing science. 2015 Jan 1;43(1):115-35.

18. Kline RB. Principles and practice of structural equation modeling. Guilford publications; 2015 Nov 3.

19. Gold AH, Malhotra A, Segars AH. Knowledge management: An organizational capabilities perspective. Journal of management information systems. 2001 May $31 ; 18(1): 185-214$.

20. Henseler J, Hubona G, Ray PA. Using PLS path modeling in new technology research: updated guidelines. Industrial management \& data systems. 2016 Feb 1;116(1):2-0.

21. Dijkstra TK, Henseler J. Consistent partial least squares path modeling. MIS quarterly. 2015 Jun 1;39(2).

22. Hu LT, Bentler PM. Fit indices in covariance structure modeling: Sensitivity to underparameterized model misspecification. Psychological methods. 1998 Dec;3(4):424.

23. Hair JF, Ringle CM, Sarstedt M. PLS-SEM: Indeed a silver bullet. Journal of Marketing theory and Practice. 2011 Apr 1;19(2):139-52.

24. Lowry PB, Gaskin J. Partial least squares (PLS) structural equation modeling (SEM) for building and testing behavioral causal theory: When to choose it and how to use it. IEEE transactions on professional communication. 2014 Apr 22;57(2):123-46.

25. Sarstedt M, Ringle CM, Smith D, Reams R, Hair Jr JF. Partial least squares structural equation modeling (PLSSEM): A useful tool for family business researchers. Journal of Family Business Strategy. 2014 Mar 1;5(1):105-15.

26. Chin WW. The partial least squares approach to structural equation modeling. Modern methods for business research. 1998 Jan;295(2):295-336.

27. Hair Jr JF, Hult GT, Ringle C, Sarstedt M. A primer on partial least squares structural equation modeling (PLSSEM). Sage publications; 2016 Feb 29.

28. Falk RF, Miller NB. A primer for soft modeling. University of Akron Press; 1992.

29. Parasuraman A, Colby CL. An updated and streamlined technology readiness index: TRI 2.0. Journal of service research. $2015 \mathrm{Feb} ; 18(1): 59-74$. 